\title{
Journal of Steel Structures \& Construction
}

\section{Structural Analysis of Lattice Steel Transmission Towers: A Review}

Lu C, Ou Y, Xing Ma* and Mills JE

School of Natural and Built Environments, University of South Australia, Australia

\begin{abstract}
Lattice Transmission Towers (LTT) and the associated transmission line systems are important infrastructure in modern society. Due to the complicated load conditions and the nonlinear interaction among the large number of structural components, accurate structural analysis of the LTT systems has been a challenging topic for many years. Still today there are some gaps between research and industrial practice. This paper presents a summary of research outcomes from current literature. Recent developments in structural modelling and failure prediction technology are reviewed in terms of connection joints, individual members and structural systems subjected to static and dynamic loads. The advantages and disadvantages of different approaches have been compared. Finally, the knowledge gaps, associated challenges and possible research directions are highlighted.
\end{abstract}

Keywords: Structural analysis; Lattice steel transmission towers; Infrastructure; Modern society; Structural components

\section{Introduction}

Safety and reliability of lattice transmission towers (LTTs) and line systems is important for modern societies. LTT system failure could result in significant economic and society impact. Apart from direct loss due to asset damage, post-disaster outages could cause huge indirect losses and severe consequences. Due to the high commercial and residential electricity consumption, high capacity and long span transmission line systems are widely used throughout the world. Such structural systems are susceptible to natural excitations, especially earthquake and wind load. Their stability and ultimate strength capacity are the primary concerns of researchers and engineers.

The structural behaviour of LTTs under static and dynamic loads have been continually studied for many years. A large number of substructural experiments have been conducted in previous decades and their results have informed full-scale tower tests. In addition, the behaviours of bolted connections have been specifically studied to complete the tower research system. Due to the development of computational structural mechanics, numerical study has become the primary research method in recent times. Many numerical simulation methods have been developed for the bolted connections, individual towers and line systems, which have been further applied to research on tower properties and structural behaviours.

This paper addresses the specific modelling methods for bolted connections, individual LTTs and line systems. The failure behaviours of non- and reinforced LTTs and line systems under static and dynamic loads are reviewed based on numerical and experimental studies. Finally, the knowledge gaps requiring further investigations are highlighted and future research directions are suggested.

\section{Loadings on transmission towers system}

In current design standards of transmission towers system in Australia and United States, which would be similar to those used worldwide, the following design loads are usually included [1,2].

Dead loads including the weight of all of the structure and its attachments are considered as the static load applying on the structures.

- Wind loads are considered as the dynamic load acting on the structures. In the academic research field, these are considered as a real-time loads, while in the practical design field, both
Australia and United States standards simplify the wind loads into static loads by considering the terrain properties, topography category, and exposure wind directions to decide the wind speed and then transform wind speed to wind pressures on tower structures [1-4].

- Accidental load, one of the compulsory loads needed to be considered in design, includes the unbalanced loads such as broken wires.

- Other loads include maintenance and construction loads, ice and earthquake loads.

These loads need to be combined for the strength and stability design through the loading factors to determine the most adverse combinations $[1,2]$. As a result, structural modelling technology for LTT system analysis also varies in terms of static load and dynamic load.

\section{Modelling of LTTs under static loads}

The overall structural behaviours of individual LTTs are not simply the superposition of the behaviours of its individual components. A steel lattice transmission tower consists of bolted connections, main structural members (e.g. leg members) and bracing systems. A tower line system consists of single towers, conductors, insulators and earth wires. In order to obtain reliable analysis results from numerical simulations, all components should be accurately modelled. In this section, the literature review focuses on the numerical modelling methods for each component in LTTs and line systems, the structural behaviours of bolted connections, LTTs and reinforced LTTs under static loads.

Modelling of bolted connections: The bolted connection is an important component in transmission tower structures. Different types of

*Corresponding author: Xing Ma, School of Natural and Built Environments, University of South Australia, SA 5095, Australia, Tel: +61 8 83023109; Fax: +61 8 83025082; E-mail: Xing.Ma@unisa.edu.au

Received June 27, 2016; Accepted June 28, 2016; Published June 30, 2016

Citation: Lu C, Ou Y, Xing Ma, Mills JE (2016) Structural Analysis of Lattice Steel Transmission Towers: A Review. J Steel Struct Constr 2: 114. doi:10.4172/24720437.1000114

Copyright: (C) 2016 Lu C, et al. This is an open-access article distributed under the terms of the Creative Commons Attribution License, which permits unrestricted use, distribution, and reproduction in any medium, provided the original author and source are credited. 
bolted connections are associated with different structural behaviours. In the mechanical model, single-bolt connections are considered as pin joints, while multi-bolt connections are regarded as semi-rigid connections. In FEM modelling, two developed methods, namely 3D modelling method and simplified modelling method, are usually employed.

3D modelling method: In most finite element programs, modelling a bolted connection follows the steps shown in Figure 1. In this method, all components are created in actual size and modelling is conducted through 3D brick elements [5] with designed material properties. Once all components are modelled, they will be assembled. Surface friction on contact regions, clamping forces and material properties will then be assigned to the model to complete the bolted connection development [6] (Figure 1).

The friction behaviour of bolted connections plays an important role in resisting shear loads between contacting surfaces. The friction force depends on bolt pretension (or clamping force) and the surface friction coefficient, the latter of which is described as $[7,8]$ :

$$
\mu=\mu_{\mathrm{k}}+\left(\mu_{\mathrm{s}}+\mu_{\mathrm{k}}\right) \mathrm{e}^{-\mathrm{d}_{\mathrm{c}} \dot{\gamma}}
$$

Where, $\mu_{\mathrm{s}}$ is the static friction coefficient, $\mu_{\mathrm{k}}$ is the kinetic friction coefficient, $\mathrm{d}_{\mathrm{c}}$ is the decay coefficient, and $\dot{\gamma}$ represents the slip rate. This function is able to simulate both the static and dynamic friction behaviours.

To create clamping forces, there are several methods in current finite element technology. Based on the theory of 'Thermal Expansion and Contraction', the 'Temperature Method' which simulates the preloading in bolted joints through temperature change has been developed and applied in previous research. The method firstly divides the original materials into several invisible layers, then the outside layer (close to the bolt cap and nut) has a relatively high temperature applied to it to allow the material to expand to simulate the tightening process [9].

The other method is the 'Deformation Method', which is developed on the basis of the 'elastic-Force-Displacement Theory'. This theory states that an elongated steel element can recover to its original length if the elongated magnitude is within its elastic range. In this method, the length of a bolt shaft is initially designed shorter than the total plate thickness. This geometry difference correspondingly develops the clamping forces through the following two steps [10-12]. In the first step, one of the bolt sides is in contact with the steel plates, while the other side of the bolt is pulled out to the location with pre-specified length. In the second step, the bolt is released to allow it to spring-back to its original length due to the effect of elastic force. With the activation of surface contact, the bolt cannot penetrate into plates and then the clamping forces are developed.
The last one is the 'Direct Method'. In this method, the elements are modelled as brick elements with actual size and material properties. Before assembling the bolted connections, an extra middle plane is required to be generated in each bolt. After assembly is accomplished, a direct pre-tension load is applied onto the middle plane. As a result, the cap and nut close to the shank start to contact the steel plates and thus create the clamping forces [5,13-18].

Finally, the well-developed plasticity model has the capability of describing the general cyclic material behaviour including cyclic strain ratcheting and stress relaxation. A detailed description of the plasticity model and the determination of material constants can be found in previous research $[9,19,20]$.

Simplified modelling method: For practical reasons, simplifications have often been employed to enable the design of transmission towers. One such simplification is to regard transmission towers as space frame structures, which has enabled designers and researchers to simplify the bolted connections as pin/hinge joints [21,22], due to its time saving and relatively reliable features.

To further improve the previous methods, the newly developed ' $3-\mathrm{D}$ pin joint', which includes joint flexibility, friction and damping features, can be employed to simulate bolted connections [23]. The failure modes and detailed results (i.e., node displacements, member forces) of the numerical models with this joint show more accurate displacement results than previous methods.

In a recent study [24], bolted connections are regarded as spring elements. The spring properties can be expressed in mathematical functions or in simple curves obtained from experiments or detailed numerical studies. In the new 'Spring Method', bolted joints are replaced by spring elements to simulate pin or semi-rigid connections. By the use of spring elements, the models not only match the experimental results but significantly reduce the modelling complexity.

\section{Modelling the individual members of steel lattice transmission towers}

Equal angle (EA) steel is the main member type used in transmission towers. There are some specific features of tower members: (1) Tower members are usually connected through bolted joints; (2) EA steel members are normally bolted on one side, hence the force transferred in members is eccentric; (3) Compression members are subject to second-order effects.

Hence, accurate simulation techniques accounting for these features are required. Research has been conducted on both theoretical and numerical nonlinear behaviours of individual beam and shell elements

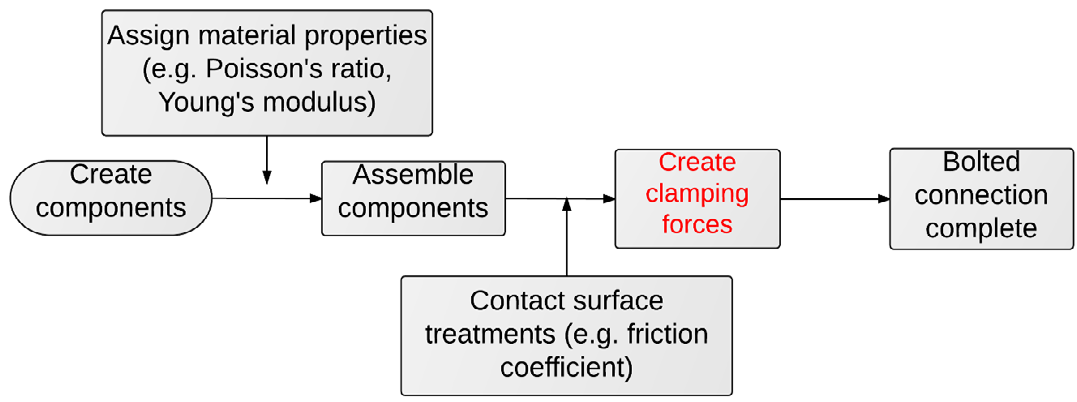

Figure 1: General steps of development of bolted connections. 
[25-29]. The findings have been applied on numerical modelling to develop transmission tower elements.

The traditional 'Beam-Column Method' is developed with the numerical beam element. In order to simulate the eccentric load, rigid links are applied between the centroid of these EA members and the load points to form extremely high stiffness to allow the eccentric load to be transferred onto the beam-column elements and to generate an extra moment [30].

The second method is the 'Beam-Column-Shell Method' which consists of two parts: beam-column elements and a middle flat-shell element. The length of shell elements is assumed as 0.2 times of the total element length for the purpose of simulating the potential plasticisation phenomenon. In addition, rigid links are used to assemble the beamcolumns and shell elements so that the loads on beam elements can be transferred onto shell elements [30].

In the 'Shell Method', EA steel members are modelled using shell elements. The potential buckling and yielding failures in different locations can therefore be considered. The top and bottom end of an EA member can be connected to beam-column elements by using rigid links [30].

The final method is a fully detailed modelling method. In this method, all EA members and bolts are modeled in 3D brick elements. This modelling approach gives the most accurate results and failure behaviours [10].

\section{Steel lattice transmission tower models}

In addition to the features of tower members, the two specific features of LTTs are: (1) usually more than one bolt is used in a connection, which forms semi-rigid joints; (2) elements in LTTs have both truss and beam features. Hence, theoretically, they cannot be simply recognized as space truss structures.

The traditional 'Truss Method' is to model the transmission towers as space truss structures, which ignores the internal forces in members induced by shear force and the moment from joints by assuming all joints as pin or hinge type $[24,31,32]$. In this way, it reduces the analysis complexity. However, the space truss modelling method presents the problem of losing structural continuity in some structural parts due to the pin feature of truss analysis. For example, the diagonal angles connect to the leg angles by multi-bolt connections, which results in a semi-rigid or rigid connection behaviours. Typically, the truss modelling method cannot initially consider this issue due to its naturally flexible assumption on joints. As for the members with onebolt connection (e.g. horizontal members connected to leg members), its in-plane behaviour can be regarded as flexible, while its torsion and bending continuity in out-of-plane cannot be initially considered in the space truss modelling method [33]. To overcome these drawbacks, extra low stiffness 'Spurious/Dummy bars' are suggested to add into models along the vertical faces [34]. However, this action dramatically increases the amount of work in structural modelling. Previous research has concluded that the truss modelling method is limited in load cases and shows considerable discrepancies in member forces by comparing results from numerical models, experiments and theoretical linear elastic truss analyses $[25,35,36]$.

The truss modelling method has unavoidable defects. However, using either beam elements or considering the transmission tower structures as a rigid frame can overemphasize the structural stiffness [33]. The straightforward solution is the 'Truss-Beam Method'. The truss element is designed to be only subjected to axial loading and to deform in the axial direction, while the beam element has extra moment and rotation freedoms in each coordinate axis $[26,36]$. Hence, the main components (e.g. leg members) and primary bracing members are regarded as beam elements, while the redundant members (e.g. secondary bracings) are considered as truss elements due to their single bolt connections at the end, low flexure stiffness and low moments transferring to other structural members $[31,36,37]$. Compared with the complexity of the truss modelling method, the truss-beam method simplifies the modelling process on which current numerical research on behaviours of transmission tower structures are based $[24,38,39]$. Its accuracy has also been proven by comparing with the results from experimental testing [40-43].

However, for the truss-beam modelling method, the detailed inspection for a specific region or member is impossible (e.g. stress concentration regions). To correct this problem, the new 'Truss-BeamShell Method', has been developed. Specifically, the shell elements can predict and express the buckling phenomenon in the main tower legs. Recently, a series of studies have been undertaken to utilise a combined beam-column and shell element modelling technique to form a tower body to study its performance $[32,42]$. This modelling technique has a great time-saving feature and is able to accurately predict the potential failure in the main tower legs.

\section{Modelling of conductors and insulators}

Conductors (i.e., the conducting wires), in reality, are heavy, flexible and swinging cable elements. Except for the end connections, they can reach free restraint conditions (i.e., free in horizontal and vertical translation and free in rotation). In the construction stage, a certain pretension force is applied to the conductors. Under strong wind action, these conductors can sway, vibrate and may even rupture. Hence, the cable elements in numerical models should be capable of simulating dynamic and highly non-linear behaviours. Insulators are the connections between towers and conductors, which work as a simple pendulum that can move in or out of plane in lattice transmission systems.

In early research, cables were modelled as tension only trusselements. Each end-node of the modelled cables had two degrees of freedom corresponding to the horizontal and vertical translations [44]. In order to simulate the prestressed construction arrangement and to avoid singularity issues [13], a very small initial tensile strain (i.e., $10^{-8}$ ) or a low temperature is required to be applied on specific conductor elements. Other researchers determined a ratio relationship ( $\alpha$ ) between the number of nodes used to divide the conductor in the model and the conductor-mode shape [45] and suggested that a ratio of at least 6 is required to obtain an accurate result.

In 2003, researchers adopted a bracing bar element to develop a relatively free model with free and restrained end in the two connected ends [46]. In addition, a so-called 'element death' option from the ADINA program was applied in the models in order to simulate a cable rupture situation. This function allows the elimination of a single or several elements along the rupture spans and transfers the dynamic effects onto the remaining line sections [47]. In order to further simulate the curvature and dynamic response of cable elements, two-dimensional consistently curved beam elements with geometric nonlinearity and meshed rules were developed [48-50].

\section{Numerical modelling techniques}

Corresponding modelling methods for non-reinforced LTTs have 
been developed. Their accuracies are verified by comparison with experimental results.

Table 1 and Figure 2 summarize the applicability of various numerical modelling elements to the different components of transmission towers and systems. In general, the truss-beam element is an overall solution for modelling tower components, whereas the shell and 3D brick element are handy for specific use, such as detailed modelling and specific buckling detection. A combined use of elements seems the most appropriate in tower system modelling, for example using truss-beam for towers and spring for conductors.

In terms of simulation accuracy, 3-D brick and shell elements definitely stand out from other methods, but their time-consuming computation brings difficulties in simulating full-scale steel LTT structures. And the bolt-slippage and dynamic effects pose further challenges to the modelling process with these two elements. From all of these previous studies it appears that the most suitable elements to model LTTs and line systems are the beam-truss element and beamtruss-shell element. These two elements offer time-saving computation combined with relatively accurate results and are capable of detecting the location for potential buckling failure (Table 1 and Figure 2).

\section{Failure Analysis of LTTs Subject to Static Loads}

\section{Bolted connections}

Bolted connections are the main load-transferring component in transmission tower systems and their efficiency is related to the structural behaviours of members and towers. Two main bolted connection types are used in transmission towers. The lap-splice bolted connection is usually used for long primary members (e.g. leg members) to form a 'continuous' member. The lapped bolted connection (singlebolt and multi-bolts) is designed for connecting secondary members (e.g. bracing) to restrain or provide extra stiffness to primary members. Previous research has described the structural behaviours of a bolted connection in parameters including bolt-pretension and relaxation percentage, bolt-slip load and the failure load [12,51-56].

The bolted-connection in transmission towers is designed with a durable clamping behaviour to preserve required performance over its lifetime. However, this ideal clamping behaviour is hard to maintain

\begin{tabular}{|l|c|c|c|c|}
\hline & Tower body & Insulator/conductor & Cable & Bolt connection \\
\hline Truss-beam & $\sqrt{ }$ & $\sqrt{ }$ & $\sqrt{ }$ & $\sqrt{ }$ \\
\hline Shell & $\sqrt{ }$ & & & $\sqrt{ }$ \\
\hline Truss-beam + shell & $\sqrt{ }$ & & & $\sqrt{ }$ \\
\hline 3D Brick & & & $\sqrt{ }$ & $\sqrt{ }$ \\
\hline Spring & & $\sqrt{ }$ & \\
\hline
\end{tabular}

Table 1: The applicability of numerical modelling elements to transmission line system components.

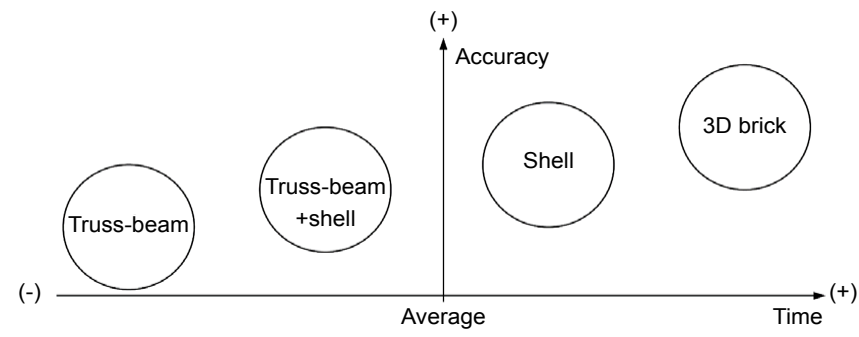

Figure 2: The comparison of modelling elements. due to time-dependent features such as changes in material properties and the condition of contact surfaces $[19,20,57,58]$. The self-loosening process starts with the gradual relaxation of initial preload. Once the clamping force is below a certain level, relative motion between fastened components occurs [56].

Early investigations [54,56] have indicated that the dynamic transverse (shear) loading on bolted connections is the most important influence factor on the self-loosening process. One of the theoretical explanations is that the dynamic loading causes internal resonant vibration of bolted connections, which results in loosening [59-62].

Compression or tension tests are the most common experimental methods for obtaining the raw structural behaviours of boltedconnections $[55,63,64]$. For the bolt-slip prediction purpose, accurate measurement of the absolute and relative displacements among different connection components is an important task. The idealized load-displacement curve is used to describe the structural behaviour of bolted connection. Four stages are included in this curve: (1) slip resistance stage; (2) bolt-slip stage; (3) bearing stage and; (4) failure stage. In the second stage, when the loading is greater than the friction resistance, bolt-slip occurs. The length of this stage is equal to the clearance between bolt shanks and the bolt holes. In the last two stages, bolt shanks touch the bolt holes and the high strength bolt shank starts to shear the bolt holes, leading to failure. The first stage, which involves many parameters such as pretension load, contract areas, surface properties, is much more complicated than the following three stages. Hence, the load-displacement curve is a general behaviour expression of bolted connections, especially for the first slip-resistance stage [64] (Figure 3).

To further discover the complexity of the first stage, a series of experimental tests were conducted on splice connections [53]. The pre-slip behaviour of splice connections is described through the slip resistance function:

$$
\mathrm{P}_{\text {slip }}=\mathrm{k}_{\mathrm{s}} \mathrm{m} \sum_{\mathrm{i}=1}^{\mathrm{n}} \mathrm{T}_{\mathrm{i}}
$$

Where $k_{s}$ is the slip coefficient, $m$ is number of slip planes, $\sum_{i=1}^{n} T_{i}$ is the sum of bolt pre-tensions, and $\mathrm{P}_{\text {slip }}$ is the bolt slip load.

These equations define the parameters that determine the bolt slip load. However, the slip coefficient varies with different steel materials.

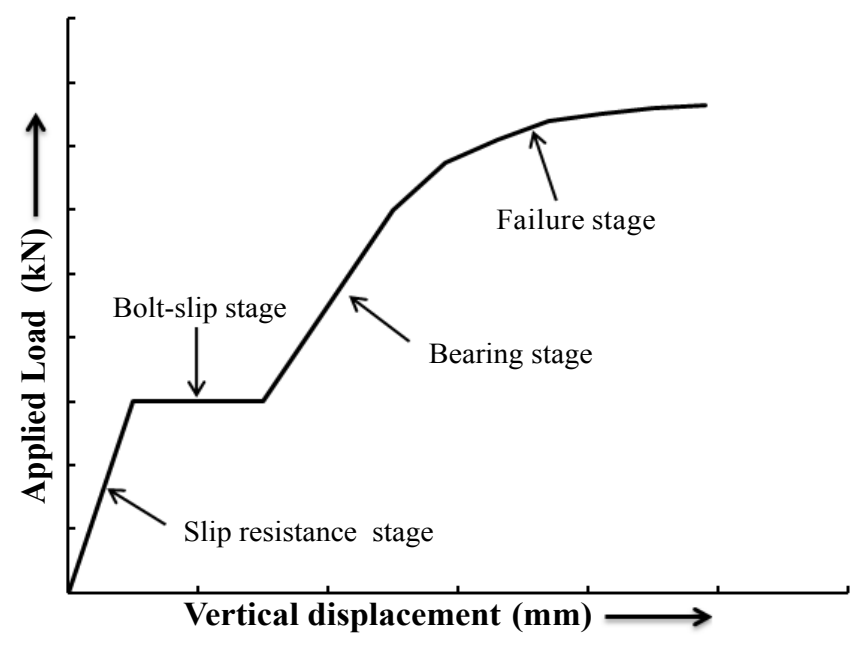

Figure 3: An example of idealized load-displacement curve. 
In addition, the surface condition and the bolt pre-tension are related to bolt types and torque application methods. The only way to apply an accurate pretension load to generate precise axial load on bolts is to calibrate individual bolts through the bolts' load-elongation curves. Once the bolt pretension load can be accurately applied, experimental tests can be conducted to obtain the slip coefficient. Another new prediction equation of slip coefficient further considers the standard deviation from individual and mean slip value [65]. In theoretical studies, bolt-slip occurs when the applied load exceeds the static frictional resistance capacity. This means the displacement in this stage should be zero or extremely close to zero. However, it is not the case in reality. Based on experimental studies, the displacement in this stage is always visible and the displacement continually increases till the bolt-slip occurs. One of the explanations for this phenomenon is 'localized slip' [52]. It is clear that the frictional force is a function of the normal force and is also indirectly related to the applied loads. Hence, both the slip force distribution and friction force distribution are not uniform within the contacted regions. As a result, some regions reach the slip condition, while others remain in a "stuck" condition. This slip on the local region is defined as 'localized slip'. This 'localized slip' is accumulated with the increase of loads or during loading cycles and finally causes the slip in entire contact regions. Later experimental and numerical studies $[52,66]$ have verified the above theories and have further concluded that compared with the shear loads that cause entire bolt slip, the minimum loading values resulting in localized slip are significantly lower. Another numerical study showed that the self-loosening caused by localized slip occurred at significantly lower transverse displacements than that caused by complete slip [13].

The third and last stage of bolted connections were studied in [53]. The third stage has the similar stiffness as the first stage, but the mechanism is totally different. In this stage, the stiffness is derived from bearing and shearing resistance between contacted plates, contacted bolts and holes rather than derived from the friction resistance as in the first stage. The connection is transferred from friction resistance type to shear and bearing type. It should be noted that the friction resistances in the third and last stage are relatively small compared with early stages. For this reason the friction resistance is neglected in these two stages. In addition, due to the bearing and shear-bearing behaviour, all loads are transferred from plates to plates against the bolts. Hence, the general load-displacement curve is not capable of expressing the details of the inner behaviour in these two stages. This is the reason that the bolt shear-stress connection deformation is chosen to describe the behaviour of bearing and failure stages.

Previous experimental research on lapped and splice lapped connections $[53,64,67]$ has found that the bearing (shearing) failure is the dominant failure mode in the final stage. It is found that the bolt hole experiences a significant elongation during the loading process and bolts have a slight rotation due to the eccentric force acting on the bolted connections, which can further accelerate the process of rotation on connected plates. Consequently, the bolted connection experiences both the bearing (shearing) failure in the local region and the overall buckling failure near the connected area $[15,53,64,67]$. Studies in [68] showed that the bolt hole elongation and ultimate strength for double or multi bolted connections was controlled not only by the material yielding strength but also by the end distance and bolt spacing. The bearing strength with tear out failure mode was proportional to the ultimate stress. The ultimate strength was also limited by the relationship of end distance and bolt spacing.

The preload loosening process includes two distinct stages $[57,69]$ :
(1) short-term loosening (Stage 1); (2) long-term loosening (Stage 2). The first stage can be very short and there is almost zero relative motion between the nut and the bolt, which corresponds to a linear and minute preload reduction on bolt pretension. In the second stage, gradual relative rotation of the fastened nut and bolt causes a sharp decrease in bolt pretension, resulting in self-loosening. In addition, a high preload results in a higher self-loosening resistance, which is approximately linear to the preload in the first stage connections [13,70]. Keeping the bolted connection in the early stage seems an appropriate approach to minimize the preload loosening phenomenon. Some further conclusions from [9] are listed below:

- Friction between the two plates does not play an important role in the self-loosening of the bolted joints, during the early stage.

- Effectively preventing the slipping of clamped parts can successfully reduce the bolt pretension loosening.

- A reduction of $1 \mathrm{kN}$ in clamping force for the bolted joints corresponds to approximately 2 degrees of relative rotation between the nut and the bolt.

- In stage 1 (early stage), the local cyclic plasticity of the material results in cyclic strain ratcheting. Its deformation causes the stresses to redistribute in the bolt, and the result is a gradual loss of clamping force with loading cycles.

\section{Failure modes of LTTs under static loads}

An early loading test on a full-scale transmission tower showed that failure resulted from the buckling of leg and cross-arm members [70]. A nonlinear analysis results showed that the dominant failure mode was buckling in the compressive legs where the plastic hinges occur in the simulation [35]. A comparison study of numerical and experimental study further detailed another failure model of a tower. The failure occurred in the lower part triggered by the elastic buckling of a hip bracing member, leading to buckling of the main diagonal bracing member, which initiated the compression leg to buckle as well, resulting in full collapse of the tower [71]. Other experimental research [25,32] of steel lattice tower structures under pushover static loads suggested that the main failure mode was found to be the elasto-plastic buckling of the main legs in the bending case, whereas the dominant failure mode in the flexure-torsion case was the buckling of the diagonal bracing members below the cross arm of the tower. In addition, whenever angle members failed due to buckling or yielding, load redistribution among neighbouring members occurred immediately. Similarly, a numerical study on the effects of residual stress and initial imperfections on the ultimate behaviour of transmission towers also indicated that the buckling failure in main leg was the main failure mode due to the P- $\Delta$ effect [51].

Full-scale numerical studies with and without joint eccentricity and joint slippage also concluded that the global collapse of the tower was caused by the inelastic buckling failure of the tower main legs $[24,72]$.

\section{Failure modes of reinforced LTTs under static loads}

Existing towers are often retrofitted in order to increase structural strength. In order to avoid the buckling failure, the hip bracing retrofitting strategy can be used to provide additional supports for legs and bracing components, resulting in a significant strength enhancement $[32,42]$. Similarly, with added diaphragms, the deflections of cross-bracing can be significantly decreased and the torsional buckling phenomenon on the main legs switches to a flexural buckling failure mode [40]. These reinforcing methods are most effective on components and towers with high slenderness ratios. 
The other main reinforcing method used to enhance the ultimate strength of a tower is attaching additional steel components to original leg segments through bolted connections. This method is most effective for leg member elements with slenderness ratios $(1 / \mathrm{r})$ below about 100 [73]. Reinforced members with two interconnectors at the $1 / 4$ and the $3 / 4$ position in a leg element have an optimum ultimate strength capacity [51]. Two or three-bolt cruciform type connections are the most effective to transfer load and provide adequate shear resistance to the connecting areas $[74,75]$.

For retrofitted LLTs, the dominant failure mode is also the buckling failure in leg segments. Pre-loading process causes a load-sharing delay between reinforcing and original leg elements, but does not change the ultimate strength upgrade [73]. A progressive failure mechanism starts from increasing displacement to plastic hinge development, and finally to the buckling failure in leg elements [76,77]. In addition, the bolted connections quality and its properties such as plate thickness, bolts numbers and arrangements change the stiffness of bracing and leg members, which in turn affect the overall stability of the tower system, which is usually determined by the buckling resistance capacity of leg elements.

\section{Dynamic Properties, Response and Failure of LTTs}

This section outlines the dynamic properties, dynamic responses and failure modes of LTTs and tower-line systems under dynamic wind actions.

\section{Dynamic properties}

In structural engineering, the natural frequency, mode shape and damping ratio are used to describe the structural dynamic properties. These properties relate to intrinsic structural features such as structural type, geometry, mass distribution, structural stiffness distribution and joint construction.

Individual LTTs, reinforced LTTs and line systems are subjected to dynamic actions, such as various types of wind actions. The LTTs have several unique features compared with other engineering structures including: 1) relatively tall but with low mass; 2 ) truss-frame structural type; 3) material and geometric nonlinearity; and 4) sway components. It is important to study the dynamic properties of LTTs in order to predict their behaviour and design them effectively.

\section{Methods for determining dynamic properties:}

Theoretical methods: All methods are developed on the basis of the equation of motion [78]:

$$
\begin{aligned}
& {[\mathrm{M}]\{\ddot{\mathrm{y}}\}+[\mathrm{K}]\{\mathrm{y}\}=0} \\
& \{\mathrm{y}\}=\{\varphi\} \sin (\omega \mathrm{t}+\theta) \\
& \left([\mathrm{K}]-\omega^{2}[\mathrm{M}]\right)\{\varphi\}=0 \\
& \left|[\mathrm{~K}]-\omega^{2}[\mathrm{M}]\right|=0
\end{aligned}
$$

where $[K]$ is the stiffness and $[M]$ is the mass of a system, $\{y\}$ is displacement, $\{\ddot{y}\}$ is acceleration, $\omega$ is the natural frequency of a structure, $\mathrm{t}$ is time, $\theta$ is the phase angle and $\{\varphi\}$ represents the corresponding shapes of the vibrating system.

These equations are very convenient for a system with a concentrated mass at its free end while other parts are weightless. But infinite segments in a continuous structure mean a complex calculation process. To make the calculation of natural frequency for a continuous structure achievable, methods integrated with simplifying techniques are developed.

The most commonly used analysis technique for continuous systems is the lumped-mass method, which can significantly save calculation time by simplifying a system to several discrete points with a proportional mass-weight [78]. In this way, the original infinite element is simplified into mass points, so that the degrees of freedom and the corresponding displacement and acceleration are only considered at these discrete locations. This simplified model is then used to perform a dynamic property analysis $[79,80]$. Another example also indicates that the simplified lumped-mass technique is accurate in eigenvalue calculations by comparing dynamic properties of a detailed model [81].

Practical methods: In early research, some natural frequency calculation methods have been developed. The most commonly used methods are: 'Rayleigh's Method' and 'Dunkerley's Method.' These classic and universal methods have been further developed to be applicable to LTTs and some new simplified methods have also been developed in recent years.

Due to the convenience provided by the lumped-mass technique, a later research improved Dunkerley's theory to be able to hand-calculate the natural frequency for an individual LTT structure by considering the specific effects of the cross-arm section [82]. The procedure is shown below:

$$
\begin{aligned}
& 1 / \mathrm{w}_{1}^{2}=\mathrm{w}_{\mathrm{bl}}^{2}+\operatorname{partial} \sum \mathrm{w}_{\mathrm{c}(\mathrm{r})}^{2} \\
& \mathrm{w}_{\mathrm{c}(\mathrm{r})}=\left[\mathrm{c}_{(\mathrm{c})} \times \mathrm{a}_{\mathrm{cc}(\mathrm{r})}\right]^{-1 / 2}
\end{aligned}
$$

where $\mathrm{W}_{\mathrm{bl}}^{2}$ is the fundamental natural frequency of the tower body, $\mathrm{W}_{\mathrm{c}(\mathrm{r})}$ is the fundamental natural frequency of the cross arms, $\mathrm{c}_{(\mathrm{c})}$ is cross arm inertia and $\mathrm{a}_{\mathrm{cc}(\mathrm{r})}$ is cross arm flexibility. Subsequently, some researchers further extended this method to asymmetrical LTTs by decomposing the original structure to several symmetric or asymmetric structures [83].

The other method developed around the middle of the 1990s is the so-called 'Cantilever Beam' method which considers a structure as a cantilever beam system and its total weight as concentrated at its free end. This method was also applied in later research [84-86].

Experimental methods: Three experimental methods are widely used to obtain dynamic properties, namely: 1) free vibration test; 2) forced vibration test; and 3) ambient vibration test. These three testing methods are used to examine structural frequencies, vibration modes and damping ratios. Equipment for these three experiments is mainly classified as three groups: 1) generator (i.e., initial force of displacement, vibration generator); 2) equipment for measuring the structural responses (i.e., sensors, amplifier and filter); 3) data recording and analysis equipment (i.e., computer and post-analysis package).

Figure 3 shows a typical arrangement of free vibration tests and forced vibration tests. To conduct a free vibration test, an initial force or displacement needs to be applied on the structure to allow the structure to freely vibrate [43]. In contrast, forced vibration tests use a vibration generator to create the resonant phenomenon. To do this, the 'sweep frequency' procedure is required where the applied vibration frequency is manually or computer controlled to detect the resonant frequency [87-89]. 
During the experiment, vibration data collected by sensors are filtered, amplified, converted into numerical data and recorded in a computer to be graphically expressed. Reading the graphic data and calculating the amplitude of vibration can determine the frequency and damping ratio. If more sensors are installed along the height of the structure, then by comparing the amplitude and vibration phase of the natural frequency, a vibration mode can be obtained. Compared with free vibration, the 'Sweep Frequency' procedure allows forced vibration tests to detect second or more natural frequencies, damping ratios and vibration modes.

The ambient vibration test is developed to detect micro fluctuating vibrations caused by human activities or environmental actions. Analysing the pulsating graph can determine natural frequencies and damping ratios. Due to its nature, this test is usually used on large scale structures such as long span cable-stayed bridges. Data is graphically expressed in a time-history curve. The natural frequencies and damping ratios can be obtained by decomposing the time-history curve using a 'Fast Fourier Transform (FFT)' function. The natural frequencies are the ones with maximum amplitude of vibration [90-93] (Figure 4).

Previous research on dynamic properties of LTTs and line systems: To understand the dynamic properties of heavy and longarm LTTs, three full-scale dynamic experiments based on the forced vibration test were conducted in Japan [87] and the results claimed that owing to the rotational inertia of the cross arms, the natural frequency of the tested tower in the transverse direction was smaller than that in the longitudinal direction. In addition, a coupled LTT line system further increased the resonance effects by expressing an even lower natural frequency at the same condition in both examined directions. It should be noted that the tower with conductors has more eigen frequencies, due to the complex nature of the structure. Hence, the need for determining both longitudinal and transverse dynamic properties was suggested by these authors. Another comparison test based on vibration measurement also indicated that conductors caused a lower frequency value in wired towers [93]. These authors also found that different frequencies in the transverse and longitudinal directions were caused by the arm sub-structures.

A similar field measurement project aiming to determine dynamic properties was conducted by the use of a forced vibration test on a circular steel frame tower [94]. Three peak frequencies corresponding to three mode shapes were found in a power spectral density vs. frequency diagram. It was highlighted that the natural frequency of the first mode was always around or below $1 \mathrm{~Hz}$ and the mode shapes were highly dependent on frequencies and damping values. Subsequently, these authors [88] conducted further detailed measurement on damping ratios of a free-standing lattice tower by the use of the forced vibration method. The results showed that the damping known as total damping $\zeta_{\mathrm{t}}$ as the sum of structural damping and aerodynamic damping, and with the increase of vibration amplitudes, damping ratios increased while natural frequencies decreased [95].

Since the mid-1990s, researchers have mainly focused on the dynamic properties of lattice transmission line systems and some valuable achievements have been obtained. A comparative test over a duration of three years on uncoupled and coupled lattice transmission line system was conducted to identify cable effects on the dynamic properties based on ambient vibration measurement in a mountainous area [91]. The results indicated that the dynamic properties of cables significantly influenced the natural frequencies and damping ratios of LTTs. A further study [96] showed that damping ratios of conductors were mostly dependent on their aerodynamic damping properties. A high correlation between wind directions and dynamic properties was also discovered through a study on the aerodynamic damping ratios of a lattice transmission line system and results concluded that the aerodynamic damping ratios of a coupled tower varied with wind directions [50].

In addition to studies on natural frequencies and damping ratios, researchers have also considered the effects of load levels on damping ratio of LTTs. An early experiment on steel buildings [97] observed a relationship between structural damping ratios and load levels. A free-vibration experiment on an individual LTT showed a significant variation with different load levels, whereas the relationships between them were not presented clearly [49]. To explain the correlation between damping ratios and applied loading magnitudes, a laboratory free vibration test was proposed on an upper part of a LTT [43]. The applied load ranged from $5 \%$ to $100 \%$ of its ultimate load capacity and the authors cyclically measured the damping ratios from one peak to another. The results indicated that the damping ratios of LTTs increased with applied load levels ranging from $0 \%$ to $40 \%$.

\section{Analysis methods of dynamic response}

The fluctuating nature of wind velocity, duration and direction can potentially excite resonant vibrations on structures. This leads to a complex response analysis. Structures with a low natural frequency (below $1 \mathrm{~Hz}$ ) are particularly vulnerable to resonance phenomena, which in turn can significantly affect structural dynamic responses [98]. Full-scale measurements have shown that LTTs usually have a natural frequency which is below or just over $1 \mathrm{~Hz}$ [98-100].

Although, this frequency value can be varied by aerodynamic damping and structural damping, it is still unpredictable. Once wind-

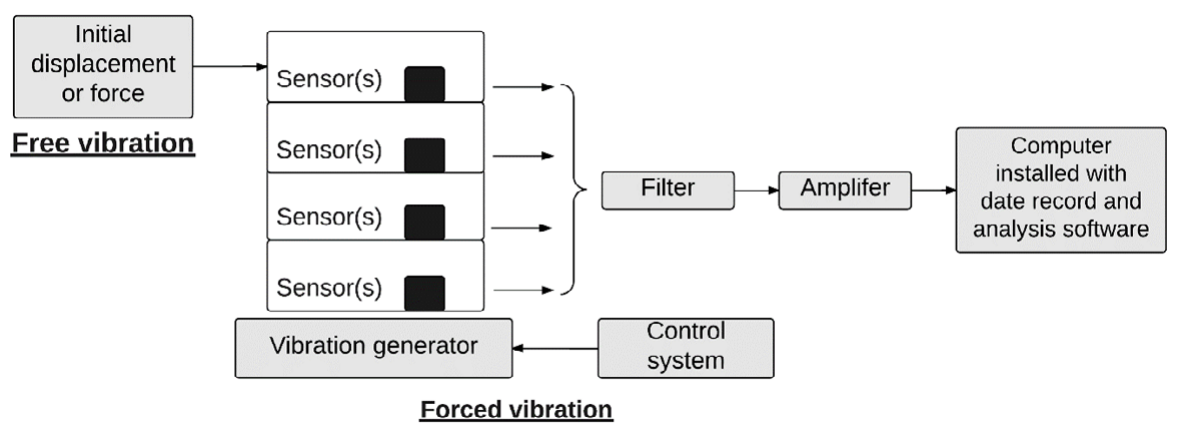

Figure 4: A typical experimental arrangement of free vibration and force vibration test. 
induced resonant responses occur on a structure, counteracting structural forces including: (1) inertial forces; (2) elastic and stiffness forces; (3) damping and energy-absorbing forces start to balance the wind forces [101]. Hence, the behaviour of a structure changes and needs to be studied carefully in order to determine the dynamic response of LTTs and line systems.

As mentioned previously, dynamic responses are dependent on time histories. Hence, the time-domain analysis method has been widely used in order to understand the dynamic responses of LTTs and line systems. The data from such analysis is presented with the amplitude (e.g. displacement, stress, acceleration) as the vertical axis and the elapsed time as the horizontal axis.

The other analysis method commonly used is the frequencydomain method, which presents the amplitude on the vertical axis and frequency on the horizontal axis. The frequency-domain curve can be obtained from the time-domain curve by the use of the 'Fast Fourier Transform (FFT)' mathematical function.

The time-domain curve superposes all harmonic Sine waves, while the frequency domain curve selects the peak amplitude for all waves, in which amplitude is the dynamic response such as displacement, member stress and accelerations. Hence, due to the nature of the timedomain method, it is difficult to identify the individual frequencies and events that are contained in the time-domain wave [102]. Whereas, the frequency-domain analysis can differentiate a discrete vibration wave from a complex spectrum or frequency dependent components [78] so that a detailed examination of dynamic responses from specific impacts can possibly be proceeded.

Previous research on dynamic responses: An early measurement of the acceleration responses of a free standing LTT was conducted under wind loadings and was analysed by the time-domain method [103]. Their results indicated that along- and cross-wind accelerations both increased monotonically and equally with the mean wind speed. In order to understand wind-induced dynamic effects, other researchers [94] undertook a full-scale measurement on a free-standing LTT and analysed the dynamic responses' relationship to wind and acceleration by the use of the time-domain method. The dynamic response (acceleration) generally increased with wind speeds and an empirical exponent function in terms of acceleration and mean wind speeds was also provided in this research project. These research findings agreed with previous full-scale site measurements [101,104]. In an ongoing study on wind-induced deflection responses, the same tower was tested with a mean wind speed applied at an angle varying from 260 to 280 degrees [105]. The obtained deflection values for both along-wind and cross-wind direction showed:

1) The deflection ratio (deflection of cross-wind / deflection of along-wind) on the background response was 0.5.

2) The resonant deflection of cross-wind and along-wind were almost equal, which unanimously agreed with several previous fullscale projects' outcomes $[103,104]$.

These results are in conflict with the Australian tower design code [2] which recommends that the much lower cross-wind excitation caused by turbulent wind could be neglected, unless there are substantial enclosed parts of the tower near the top. Hence, Clause 2.3.6 in the existing Australian tower design code - AS 3995 [2] potentially underestimates the effect from the cross-wind response.

A galloping amplitude study on a steel lattice transmission line system was undertaken on a three span line system by the use of a computational simulation program [99]. These authors suggested that a dynamic effect inspection from coupling spans was necessary to obtain more conservative estimated galloping amplitudes. Later, a measurement on a lattice transmission line system showed a high dependency between wind speeds and dynamic responses using the time-domain analysis method [91]. In this research, accelerations proportionally increased with wind speeds and the responses of the lattice transmission line system were greatly influenced by the conductors. Specifically, member strain variation with conductors was researched and it was found that more strain peaks were detected at the low frequency region in the model with conductors. Similarly, the aerodynamic damping of cables could be higher than $60 \%$ of critical damping, which greatly influenced the cables ' behaviour, and in turn played an important role in the dynamic responses of lattice transmission line system [106].

A numerical study on a self-supporting steel lattice transmission line system conducted by adopting the time-domain and frequency-domain analyses indicated that swaying conductors had significant dynamic effects on fluctuating responses in both directions and dominated the vibration modes of the line systems [46]. A further study focusing on dynamic responses indicated that the swaying of conductors under different wind conditions changed the dynamic responses of LTTs and therefore the authors suggested that proper protection should be taken into consideration when towers were subjected to heavy wind conditions [107]. A full-scale response measurement on a steel lattice transmission line system using the time-domain method was conducted to obtain the relationship of members' strain and wind speeds and concluded that the mean member strain followed the power load with a proportional factor equal to 2 [108]. A recent study using energy criteria to assess the dynamic responses of LTTs and line systems found that the total windinduced energy was equal to the sum of kinetic energy, strain energy and the energy dissipated by structural damping [109]. Moreover, an internal transition mechanism was detected in kinetic energy and strain energy. The peak values of kinetic energy occurred at the same time as the minimum of strain energy and vice versa.

\section{Dynamic failure of LTTs}

The rupture of cables under strong winds is one of the main reasons for collapse of lattice transmission line systems [46]. Another failure assessment of a transmission tower in Canada due to a microburst wind and its corresponding numerical model indicated that the progressive failure mechanism starts from the end of conductor's cross-arm [77]. Additional test results suggested that eccentric compression and unbalanced deformation in the main legs trigger the bending moment, leading to buckling failure which was the dominant failure mode for the tower sub-assemblage [23].

A numerical collapse simulation of steel lattice transmission line systems verified that the resonant responses of high vibration modes led to a reversal of internal forces in certain structural members. Importantly, several internal member forces were four to five times greater than those found in the first vibration [39]. Similarly, numerical simulation in $[110,111]$ showed that in a higher vibration mode, bracing members were more critical than leg members, because they were subjected to a high axial stress. Another recent study considered windinduced responses on LTTs based on numerical simulation models and found that movement of conductors and earth wires could result in failure due to the maximum internal force on members exceeding the design load by up to $65 \%$. These authors further indicated that: 1 ) wind load directions severally affected the dynamic behaviours of line 
systems, 2) with damping contributions, the critical leg member stress decreased gradually [112].

Very recently, a further study on failure behaviours has been undertaken on a numerical model of a steel lattice transmission line system [38]. These authors modelled a line system by connecting tower models with cable elements and tested them in various wind conditions. Their results indicated that the collapse types and directions mostly corresponded to the last instantaneous deformations caused by structural element failures. In addition, predicted collapses and failure locations by the use of an individual transmission tower were not accurate. The recommended solution was therefore to include conductors and earth wires to connect single LTTs into line systems.

\section{Conclusions and Suggestions}

This paper summarizes recent research achievements on lattice transmission towers and line systems. The numerical modelling methods are reviewed from bolted connections and tower elements to individual towers and line systems. The research findings on static and dynamic behaviours of bolted connections have been summarized and discussed through the load-displacement curve and bolt pretension degeneration situation. The static structural behaviours and failure modes of non-reinforced and reinforced LTTs are reviewed. The dynamic properties and the dynamic structural responses for both LTTs and line systems have then been summarized.

The transmission tower industry is a well-developed field and the research to date is quite extensive. However, there are still some knowledge gaps that need to be addressed as follows:

(1) Specific modelling methods for LTTs and line systems need to be developed. Advanced FEM technology with the capability of considering bolted connection behaviours and detecting failure mode needs further investigation.

(2) The research on retrofitted LTTs is not sufficient: the structural behaviours of reinforced steel LTTs and the differences from original LTTs need additional research. The dynamic properties and dynamic responses for reinforced LTTs and line systems have not yet been researched sufficiently.

\section{References}

1. American Society of Civil Engineers (2009) ASCE Manual 74, Guidelines for electrical transmission line structural loading, ASCE, New York.

2. Standards Australia (1994) AS 3995-1994, Design of steel lattice towers and masts, Standards Australia, NSW.

3. American Society of Civil Engineers (2009) ASCE Manual 7, Minimun Design Loads for Buildings and Other Structures, ASCE, New York.

4. Standards Australia (2011) AS/NZS 1170.2: 2011 Structural design actionsPart 2: Wind actions, Standards Australia, NSW.

5. Brunesi E, Nascimbene R, Rassati GA (2014) Response of partiallyrestrained bolted beam-to-column connections under cyclic loads. Journal of Constructional Steel Research 97: 24-38.

6. Luan Y, Guan Z-Q, Cheng G-D, Liu S (2012) A simplified nonlinear dynamic model for the analysis of pipe structures with bolted flange joints. Journal of Sound and Vibration 331: 325-344.

7. ANSYS Workbench User`s Guide (2013) ANSYS, Inc., Release 15.0.

8. Oden J, Martins J (1985) Models and computational methods for dynamic friction phenomena. Computer methods in applied mechanics and engineering 52: $527-634$

9. Jiang $\mathrm{Y}$, Zhang M, Lee C-H (2003) A study of early stage self-loosening of bolted joints. Journal of Mechanical Design 125: 518-526.
10. Zhuge $Y$, Mills JE, Ma $X$ (2012) Modelling of steel lattice tower angle legs reinforced for increased load capacity. Engineering Structures 43: 160-168.

11. Nemati N, Le Houedec D, Zandonini R (2000) Numerical modelling of the cyclic behaviour of the basic components of steel end plate connections. Advances in Engineering Software 31: 837-849.

12. Citipitioglu A, Haj-Ali R, White D (2002) Refined 3D finite element modeling of partially-restrained connections including slip. Journal of constructional Steel research 58: 995-1013.

13. Huda F, Kajiwara I, Hosoya N, Kawamura S (2013) Bolt loosening analysis and diagnosis by non-contact laser excitation vibration tests. Mechanical Systems and Signal Processing 40: 589-604.

14. Mashaly E, El-Heweity M, Abou-Elfath H, Osman M (2011) Finite element analysis of beam-to-column joints in steel frames under cyclic loading. Alexandria Engineering Journal 50: 91-104.

15. Draganić H, Dokšanović T, Markulak D (2014) Investigation of bearing failure in steel single bolt lap connections. Journal of Constructional Steel Research 98: 59-72.

16. Abou-zidan A, Liu Y (2015) Numerical study of unstiffened extended shear tab connections. Journal of Constructional Steel Research 107: 70-80.

17. Wang M, Shi Y, Wang Y, Shi G (2013) Numerical study on seismic behaviors of steel frame end-plate connections. Journal of Constructional Steel Research 90: $140-152$.

18. Qiang X, Jiang X, Bijlaard FS, Kolstein H, Luo Y (2015) Post-fire behaviour of high strength steel endplate connections-Part 2: Numerical study. Journal of Constructional Steel Research 108: 94-102.

19. Jiang Y, Sehitoglu H (1996) Modeling of cyclic ratchetting plasticity, part I: development of constitutive relations. Journal of Applied Mechanics 63: 720725

20. Jiang $Y$, Sehitoglu $H$ (1996) Modeling of cyclic ratchetting plasticity, Part II: comparison of model simulations with experiments. Journal of Applied Mechanics 63: 726-733.

21. Knight G, Santhakumar A (1993) Joint effects on behavior of transmission towers. Journal of Structural Engineering 119: 698-712.

22. Wang DQ, Boresi AP (1992) Theoretical study of stability criteria for X-bracing systems. Journal of engineering mechanics 118: 1357-1364.

23. Moon BW, Park JH, Lee SK, Kim J, Kim T, et al. (2009) Performance evaluation of a transmission tower by substructure test. Journal of Constructional Steel Research 65: 1-11.

24. Jiang W Q, Wang ZQ, McClure G, Wang GL, Geng JD (2011) Accurate modeling of joint effects in lattice transmission towers. Engineering Structures 33: $1817-1827$.

25. Lee PS, McClure G (2007) Elastoplastic large deformation analysis of a lattice steel tower structure and comparison with full-scale tests. Journal of Constructional Steel Research 63: 709-717.

26. Lee PS, McClure G (2006) A general three-dimensional L-section beam finite element for elastoplastic large deformation analysis. Computers \& Structures 84: 215-229.

27. Albermani F, Kitipornchai S (1990) Nonlinear analysis of thin-walled structures using least element/member. Journal of structural engineering 116: 215-234

28. Shan L, Peyrot AH (1988) Plate element modeling of steel angle members Journal of Structural Engineering 114: 821-840.

29. Cho S, Chan S (2008) Second-order analysis and design of angle trusses, Part II: Plastic analysis and design. Engineering Structures 30: 626-631.

30. Prasad RN, Kalyanaraman V (2001) Non-linear behaviour of lattice panel of angle towers. Journal of Constructional Steel Research 57: 1337-1357.

31. Xiao Q, Zhou L, Cai J (2012) Analysis on 500kV compact and narrow basa transmission tower in ANSYS modeling and dynamic properties. Proceedings of International Conference on Informatics, Cybernetics, and Computer Engineering (ICCE), Melbourne.

32. Prasad RN, Samuel Knight GM, Lakshmanan N, lyer NR (2010) Investigation of transmission line tower failures. Engineering Failure Analysis 17: 1127-1141.

33. YanZhong J, Qinglian X, Hua L (2009) Failure analysis of transmission tower 
under the effect of ice-covered power transmission line. Proceedings of Information Science and Engineering (ICISE), Nanjing, China. pp: 4301-4304.

34. Albermani F, Mahendran M, Kitipornchai S (2004) Upgrading of transmission towers using a diaphragm bracing system. Engineering structures 26: 735-744.

35. Albermani FGA, Kitipornchai S (2003) Numerical simulation of structural behaviour of transmission towers. Thin-Walled Structures 41: 167-177.

36. Da Silva JGS, Vellasco PCGdS, de Andrade SAL, de Oliveira MIR (2005) Structural assessment of current steel design models for transmission and telecommunication towers. Journal of Constructional Steel Research 61: 1108-1134.

37. Savory E, Parke GAR, Zeinoddini M, Toy N, Disney P (2001) Modelling of tornado and microburst-induced wind loading and failure of a lattice transmission tower. Engineering Structures 23: 365-375.

38. Zhang Z Q, Li HN, Li G, Wang WM, Li T (2013) The numerical analysis of transmission tower-line system wind-induced collapsed performance. Mathematical Problems in Engineering. pp: 11.

39. Fu D, Yang F, Li Q, Yang J (2010) Simulations for tower collapses of 500kV Zhengxiang transmission line induced by the downburst. Proceedings of International Conference on Power System Technology Hangzhou, China.

40. Xie Q, Sun $L$ (2012) Failure mechanism and retrofitting strategy of transmission tower structures under ice load. Journal of Constructional Steel Research 74 26-36.

41. Wei C, Ma B, Su T (2012) Research on the wind-induced vibration coefficient of transmission tower-line system. Physics Procedia 24: 149-154.

42. Prasad RN, Knight GMS, Mohan SJ, Lakshmanan N (2012) Studies on failure of transmission line towers in testing. Engineering Structures 35: 55-70.

43. Taillon J-Y, Légeron F, Prud'homme S (2012) Variation of damping and stiffness of lattice towers with load level. Journal of Constructional Steel Research 71: 111-118.

44. Roshan FM, McClure G (1998) Numerical modelling of the dynamic response of ice-shedding on electrical transmission lines. Atmospheric Research 46: 1-11.

45. Takeuchi M, Maeda J, Ishida N (2010) Aerodynamic damping properties of two transmission towers estimated by combining several identification methods. Journal of Wind Engineering and Industrial Aerodynamics 98: 872-880.

46. Battista RC, Rodrigues RS, Pfeil MS (2003) Dynamic behavior and stability of transmission line towers under wind forces. Journal of Wind Engineering and Industrial Aerodynamics 91: 1051-1067.

47. McClure G, Lapointe M (2003) Modeling the structural dynamic response of overhead transmission lines. Computers \& Structures 81: 825-834.

48. Koziey BL, Mirza FA (1994) Consistent curved beam element. Computers \& Structures 51: 643-654.

49. Ostendorp M (1997) Damping characteristics of a steel lattice structure in: Part 2 (of 2). Proceedings of the 1997 15th Structures Congress. pp: 358-362.

50. Shehata AY, El Damatty AA, Savory E (2005) Finite element modeling of transmission line under downburst wind loading. Finite Elements in Analysis and Design 42: 71-89.

51. Temple MC, Sakla SSS, Stchyrba D, Ellis D (1994) Arrangement of interconnectors for starred angle compression members. Canadian Journal of Civil Engineering 21: 76-80.

52. Pai N, Hess D (2002) Experimental study of loosening of threaded fasteners due to dynamic shear loads. Journal of sound and vibration 253: 585-602.

53. Kulak GL, Fisher JW, Struik JH (1987) Guide to design criteria for bolted and riveted joints. ( $1^{\text {st }}$ edn $)$, John Wiley \& Sons.

54. Finkelst RJ (1972) How much shake can bolted joints take. Machine Design 44: 122.

55. Ungkurapinan N, Chandrakeerthy SRDS, Rajapakse RKND, Yue SB (2003) Joint slip in steel electric transmission towers. Engineering Structures 25: 779-788.

56. Junker GH (1969) New criteria for self-loosening of fasteners under vibration. SAE Technical Paper.

57. Jiang Y, Zhang M, Park TW, Lee CH (2004) An experimental study of selfloosening of bolted joints. Journal of Mechanical Design 126: 925-931.
58. Jaglinski T, Nimityongskul A, Schmitz R, Lakes RS (2006) Study of bolt load loss in bolted aluminum joints. Journal of Engineering Materials and Technology 129: 48-54.

59. Hess D, Sudhirkashyap S (1997) Dynamic loosening and tightening of a singlebolt assembly. Journal of vibration and acoustics 119: 311-316.

60. Daadbin A, Chow $Y$ (1992) A theoretical model to study thread loosening Mechanism and machine theory $27: 69-74$.

61. Hess D, Davis K (1996) Threaded components under axial harmonic vibration, part 1: experiments. Journal of vibration and acoustics 118: 417-422.

62. Hess D (1996) Threaded components under axial harmonic vibration, part 2 kinematic analysis. Journal of vibration and acoustics 118: 423-429.

63. Reid JD, Hiser NR (2005) Detailed modeling of bolted joints with slippage Finite Elements in Analysis and Design 41: 547-562.

64. Ungkurppinan N (2000) A study of joint slip in galvanized bolted angle connections. Department of Civil and Geological Engineering, Master of Science in Civil Engineering, University of Manitoba.

65. Cruz A, Simões R, Alves R (2012) Slip factor in slip resistant joints with high strength steel. Journal of Constructional Steel Research 70: 280-288.

66. Pai N, Hess D (2002) Three-dimensional finite element analysis of threaded fastener loosening due to dynamic shear load. Engineering Failure Analysis 9: 383-402.

67. Frank KH, Yura JA (1981) An experimental study of bolted shear connections National Technical Information Service.

68. Kim HJ (1996) The effect of end distance on the bearing strength of bolted connections. Master of Science in Engineering, University of Texas, USA.

69. Qiang X, Li S (2013) Experimental Study on the mechanical behavior and failure mechanism of a latticed steel transmission tower. Journal of Structural Engineering 139: 1009-1018.

70. Jiang Y, Zhang M, Park TW, Lee CH (2002) An experimental investigation on frictional properties of bolted joints. Proceedings of ASME Pressure Vessels and Piping Conference, Vancouver, BC, Canada.

71. Albermani F, Kitipornchai S, Chan RWK (2009) Failure analysis of transmission towers. Engineering Failure Analysis 16: 1922-1928.

72. Jiang WQ, Wang ZQ, McClure G (2010) Failure analysis of lattice transmission tower considering joint effects. Proceedings of Computer Application and System Modeling (ICCASM), BaoDing, China.

73. Mills JE, Ma X, Zhuge $Y$ (2012) Experimental study on multi-panel retrofitted steel transmission towers. Journal of Constructional Steel Research 78: 58-67.

74. Tongkasame C (2008) Retrofitting of angle legs of transmission towers to increase load capacity. School of Natural and Built Environments, PhD of CivilEngineering, University of South Australia, Australia.

75. Denton J, Windsor D, Mills JE, Tongkasame C, Zhuge Y (2005) Effectiveness of load sharing connections for the reinforcement of steel lattice tower leg members. Australian Structural Engineering Conference. pp: 1054-1063.

76. Szafran J (2015) An experimental investigation into failure mechanism of a fullscale $40 \mathrm{~m}$ high steel telecommunication tower. Engineering Failure Analysis 54: 131-145.

77. Shehata A, El Damatty A (2008) Failure analysis of a transmission tower during a microburst. Wind and Structures 11: 193-208.

78. Clough RW, Penzien J (1993) Dynamics of structures. McGraw-Hill, New York.

79. Wu JC, Yang JN (1998) Active control of transmission tower under stochastic wind. Journal of Structural Engineering 124: 1302-1312.

80. Feng MQ, Zhang R (1997) Wind-induced vibration characteristics of Nanjing TV tower. International Journal of Non-Linear Mechanics 32: 693-706.

81. Lavassas I, Nikolaidis G, Zervas P, Efthimiou E, Doudoumis IN, et al. (2003) Analysis and design of the prototype of a steel 1-MW wind turbine tower Engineering Structures 25: 1097-1106.

82. Trainor PGS, Popplewell N, Shah AH, Wong CK (1985) Estimation of fundamental dynamic characteristics of transmission towers, power apparatus and systems. IEEE Transactions 104: 681-689.

83. Trainor PGS, Shah AH, Popplewell N (1986) Estimating the fundamenta 
Citation: Lu C, Ou Y, Xing Ma, Mills JE (2016) Structural Analysis of Lattice Steel Transmission Towers: A Review. J Steel Struct Constr 2: 114. doi:10.4172/2472-0437.1000114

natural frequency of towers by Dunkerley's method. Journal of Sound and Vibration 109: 285-292.

84. Posiadała B (1997) Free vibrations of uniform timoshenko beams with attachments. Journal of Sound and Vibration 204: 359-369.

85. Murtagh PJ, Basu B, Broderick BM (2004) Simple models for natural frequencies and mode shapes of towers supporting utilities. Computers \& Structures 82: 1745-1750.

86. Auciello NM (1996) Transverse vibration of a linearly tapered cantilever beam with tip mass of rotary inertia and eccentricity. Journal of Sound and Vibration 194: 25-34.

87. Maeno Y, Hanada K, Sakamoto Y, Yamagishi H (1984) Dynamic properties of UHV power transmission towers: full-scale tests and numerical investigation. Proceedings of the 8th WCEE, San Francisco, America. pp: 929-936.

88. Glanville MJ, Kwok KCS, Denoon RO (1996) Full-scale damping measurements of structures in Australia. Journal of Wind Engineering and Industrial Aerodynamics 59: 349-364.

89. Nie Q, Nieh CD, Cai J, Zhang M (1989) The natural frequencies of coupled inline towers. Journal of Sound and Vibration 134: 17-28.

90. Magalhães F, Caetano E, Cunha Á, Flamand O, Grillaud G (2012) Ambient and free vibration tests of the Millau Viaduct: Evaluation of alternative processing strategies. Engineering Structures 45: 372-384.

91. Momomura Y, Marukawa H, Okamura T, Hongo E, Ohkuma T (1997) Full-scale measurements of wind-induced vibration of a transmission line system in a mountainous area. Journal of Wind Engineering and Industrial Aerodynamics 72: 241-252.

92. Liu X (2011) The study on modal analysis theory and measurement method for transmission towers. Proceedings of Mechanic Automation and Control Engineering (MACE), Nanjing, China.

93. Lee CY, Huang NE, Chern CC, Su SC (2012) A study on the dynamic characteristics and ultimate capacity of steel transmission towers. Journal of the Chinese Institute of Engineers 36: 273-294.

94. Glanville MJ, Kwok KCS (1995) Dynamic characteristics and wind induced response of a steel frame tower. Journal of Wind Engineering and Industrial Aerodynamics 54: 133-149.

95. Tamura Y, Yamada M, Yokota H (1994a) Estimation of structural damping of buildings. Proceedings of ASCE Structural Congr and IASS Int Symp.

96. Maeda J, Morimoto Y, Ishida N, Tomokiyo E, Imamura Y (2003) Aero-dynamic damping properties of a high-voltage transmission tower. Proceedings of the structural engineers world congress. pp: 255-262.

97. Holmes JD (2001) Dynamic response and effective static load distributions. Spon Press.
98. Holmes J (1996) Along wind response of lattice towers-III. Effective load distributions, Engineering Structures 18: 489-494.

99. Desai YM, Yu P, Popplewell N, Shah AH (1995) Finite element modelling of transmission line galloping. Computers \& Structures 57: 407-420.

100.Denoon RO, Kwok KCS (1996) Full-scale measurements of wind-induced response of an $84 \mathrm{~m}$ high concrete control tower. Journal of Wind Engineering and Industrial Aerodynamics 60: 155-165.

101. Glass T, Cook BW, Banks RW, Schafer BL, Holmes JD (1990) The dynamic characteristics and response to wind of tall free-standing lattice towers. Proceedings of IEA Structural Engineering Conference, Barton, ACT.

102. Mobley RK (1999) Vibration Fundamentals. Butterworth-Heinemann.

103. Holmes JD, Schafer BL, Banks RW (1992) Wind-induced vibration of a large broadcasting tower. Journal of wind engineering and industrial aerodynamics 43: 2101-2109.

104. Hiramatsu K, Akagi $H$ (1988) The response of latticed steel towers due to the action of wind. Journal of Wind Engineering and Industrial Aerodynamics 30: 7-16.

105. Glanville MJ, Kwok KCS (1997) Wind-induced deflections of freestanding lattice towers. Engineering Structures 19: 79-91.

106. Loredo-Souza AM, Davenport AG (1998) The effects of high winds on transmission lines. Journal of Wind Engineering and Industrial Aerodynamics 74: 987-994.

107. Sun B, Hou L, Guang Z, Wang L, Fu G, et al. (2010) Study of dynamic response of overhead transmission lines to different wind speeds. Proceedings of High Voltage Engineering and Application (ICHVE), New Orleans, LA.

108. Okamura T, Ohkuma T, Hongo E, Okada H (2003) Wind response analysis of a transmission tower in a mountainous area. Journal of Wind Engineering and Industrial Aerodynamics 91: 53-63.

109. Pengyun L, Jiedong L, Ming N, Wanli Z, Anguo H (2012) Dynamic response of power transmission towers under wind load. Energy Procedia 17: 1124-1131.

110. Gan F, Peng Y (2009) Numerical analysis on wind-induced vibration of long span power transmission towers. Proceedings of Information Science and Engineering (ICISE), Nanjing, China.

111. Yasui H, Marukawa H, Momomura Y, Ohkuma T (1999) Analytical study on wind-induced vibration of power transmission towers. Journal of Wind Engineering and Industrial Aerodynamics 83: 431-441.

112. Yang J, Yang F, Li Q, Fu D, Zhang Z (2010) Dynamic responses analysis and disaster prevention of transmission line under strong wind. Proceedings of Power System Technology (POWERCON), Hangzhou, China. 